$\begin{array}{llll}K & R & \text { I } & \text { Z }\end{array}$

Kriz Dergisi 12 (1): 47-53

\title{
ERGENLERDE GELişiMSEL KRiz ÜZERINE BiR KLiNiK ÖRNEK
}

\author{
Seda Haran*
}

\section{ÖZET}

Ergenlik çocukluk ve yetişkinlik arasında bir morotoryumdur. Ergenlik değişim ve büyừmeyi içine alır. Bu dönem bittiğinde ergen belli bir kimliğe sahip bireyselleşmiş ve ayrışmış bir birey olmalıdır. Bu dönemin zorlayıı deneyimleri meslek seçimi, değerler sisteminin ve yaşam felsefesinin oluşturulması ve yakın ilişkiler kurma konusunda yaşanır. Gençler bu evrede özerk bir birey olmakla, toplumun uyumlu bir üyesi olmayı bağdaştırma durumundadır. Gençlerin gelişimsel yaşam krizleri genellikle ana-baba ile yaşanan çatışmalar, okulda yaşanan başarısızlıklar, kendi cinsinden ve karşı cinsten yaşıtlarıyla ilişkide çıkan sorunlarla oluşur. Gençler için özellikle bir grubun ũyesi olma gereksinimi, dışlanma korkusuyla bazı alt kültür gruplarına katıımasına yol açar. Bu çalışmada gelişimsel yaşam krizi yaşayan bir

Uzm. Psk., Ankara Üniversitesi Psikiyattik Kriz Uygulama ve Araştırma Merkezi. ergen ve ailesiyle yürütülen tedavi programı sunulmuştur.

Anahtar Sözcükler: Ergen, gelişimsel yaşam krizleri, kimlik, aite.

\section{A Clinical Case on Developmental Crisis in The Adolescence Period}

\section{SUMMARY}

Puberty is the morotorium between childhood and adulthood periods. $H$ includes both development and growth. An adolescent should have a notable identity with the dififerentiated individualization by the and of this period. The forced experiences of puberty is on the selection of any kinds of profession to be built up valves systems and life philosophy. Young's have experienced some kinds of conflicts between to be an independent individualization and to be an adaptive person. In this condition puberty is a kind of reconciliation period. The developmental crisis of youngs have generally accented with conflict with parents, unsuccess- 
fuly ness in school, their peer relation and the problems with thenselves. The need of belonging to a groups leads young's to join subcultures groups. In this study, presented crisis intervention program on an adolescent with developmental crisis and his/her family.

Key Words: Adolescent, developmental crisis, identity, family.

\section{GiRiş}

"Büyümek", "Yetişkinliğe Erişmek" anlamına gelen "adolescence" yani ergenlik günümüze gelinceye kadar değişik şekillerde tanımlanmıştır. Ergenlik değişim ve büyümek demektir. Aynı zamanda başkalaşım (metamorphose) ve dönūşümü (mutation) de içerir. Ergenlik döneminde birey hem bedensel, hem ruhsal, hem de toplumsal alanda değişime, đönüşüme uğrar (Paiman 1997).

Sieg (1971) "ergenliğe insanda bireyi yetişkine özgü ayrıcalıklarının kendisine verilmediğini hissettiği zaman başlayan ve yetişkinin tüm gücü ve toplumsal konumu toplum tarafından bireye verildiği zaman sona eren gelişim dönemi" olarak tanımlar. Schulz (1972) ise ergenliğj "genç yetişkine değişik yetişkinlik rollerini vatandaşlik sorumlulư̛̆unun sonuçlarına katianmak zorunda kalmadan denemesine izin verildiğinde yaşanan negatif bunalım” biçiminde tanımlamaktadır (Gander, Gardiner 1993).

Genellikle kabul edildiği gibi ergenlik erken ergenlik aşamasında puberteye bağlı bedense! değişikliklerle başlayan ve adolesanın gerçekçi bir şekilde kişiliğini bulmasına kadar süren çeşitli ve çok boyutlu gelişimsel sorunların yaşandığı ve çŏzümlendiği bir dönemdir. $\mathrm{Bu}$ gelişimsel sorunlar duygusal alanda bir karmaşaya düşünce ve davranışlarda anlaşııması güç değişmelere yol açar. Dürtülerdeki kabarma ve şiddetlenme ego üzerinde bozucu bir etkiye neden olur. Dolayısıyla pek çok yazar tarafından "fırtına ve stresler" dönemi olarak tanımlanan bu dōnem bu özellikleriyle kendisi bir kriz özelliğj taşır.

Biyolojik olarak ergen vücudunda meydana gelen değişimlere uyum sağlamak ve bunlara bağlı ortaya çıkan cinsel dürtülerle baş etmek konumundadır. Dönemsel olgunlaşmaya parale! olarak ortaya çıkan bilişsel yetiler ergeni hem kendisiyle hem de çevresiyle ilgili yeni değerlendirmeler ve soyutlamalara iter Erickson'a (1968) göre Ergenlik döneminde kimlik gelişimi önem kazanır ve bu dönemin getişimsel ödevidir. Kimlik sorunları yaşam boyu sürse bile en çok bu evrede ağırlık taşır. Ergen için psikolojik anlamda bağımsızłığını kazanabilme, kendine yön verecek yeni değerler bulma ve benimseme sorunu önem kazanır. Yeni arayışlar içinde olan genç mevcut değerler ve hayatın anlamını sorgular. Gençler bu evrede özerk bir birey olmakla, toplumun uyumlu bir üyesi olmayı bağdaştırma durumundadır. Bu dönemde genellikle ana-baba ile yaşanan çatışmalar, okulda yaşanan başarısızlıklar, kendi cinsinden ve karşı cinsten akrantarıyla ilişkide çıkan sorunlar dikkatj çeker. Gençler için özellikle bir gruba uyma gereksinimi bazen kendilerine zarar verecek alt kültưr gruplarına katılmalarına yol açar. Bazen de yaşadıkları kişiler arası çatışmalar ve yoksunluklar sonucu sağlıklarını bozucu maddelere ya da yaşamı tehdit edici davranışlara yönelirler.

Ergen ailesiyle de çatışmalar yaşar. Kimlik gelişimi sürerken yetişkin davranışı ile çocuksu 
davranışı çoğu kez karıştırır. Gencin aileden bağımsız olma çabalarında çelişkili duyguları çoğunlukla artar. Hem onlardan uzaklaşma ve bağımsızlaşma isteği hem de onların desteğine ve sevgisine intiyaç đuyma ikilemi içindedir. Diğer yandan ailenin duyguları çoğu kez ikizlidir. Hem gencin artık büyümesini ister. Hem de ona hala çocukluktaki gibi davranma eğilimi gösterilir. Genç kendi gözünde kendini bưyütmüş ve değişmiş görmek ister. Daha özerk karar verebilmek, kendi seçimini yapabilmek, kendi değer yargıtarına sahip olmak isterken yeni rollerinden emin değildir. Bu nedenle hem anne babanın kendine destek olmasına intiyaç duyar, hem de kendi içinde bu isteğe karşı koymaya çalışır. Ergen kendisi için önemli olan kişilere gereksinim duymadığını kendi kendine kanıtlamaya çalışırken şimdiye kadar yeterli gördüğü anne babasının ve diğer önemli kişilerin bu yeterli yönlerini yadsımaya başlar. Böylece aileye ve diğer otorite figürlerine daha fazla gereksinim duymasından ileri gelen içsel çatışmayı geçici olarak çözmüş, kendini onların desteğine gerek duymaz halde görmeye başlamıştır.

$\mathrm{Bu}$ çatışmalar sırasında çocukluktan itibaren kendisine sevgi vermiş olan anne ve babadan uzaklaşmaya başlar. Aynı zamanda anne-baba sevgisinin kaybı nedeniyle büyük bir yalnızlık ve hüzün duyar. Bu durumda aile dişında yeni sevgi kaynakları aramaya başlar. Akran grubu ve arkadaşlık kendisi için olağanüstü önem kazanır. Çünkü anne baba egmenliğine, onların değer yargılarına ve kendi yaşamına karışmalarına az veya çok karşı çıkabilmiş olan genç artık toplumda birilerine ait olma özlemini duymaktadır (Ekşi 1999).

\section{OLGU}

19 yaşında, bekar, kadın hasta, üniversite birinci sınıf ŏgrencisi N.Ç. için randevuyu annesi
A.Ç. bir arkadaşının tavsiyesi üzerine telefonla arayarak aldı. Anne ile bir görüşme yapıldıktan sonra N.Ç. için bir randevu verildi.

A.Ç. ilk görüşmede çok sıkıntılı huzursuz ve endişeli olarak gözlendi. Kızının içinde bulunduğu durumu kabullenemiyor ve ona karşı öfkeli olduğu gözleniyordu.

A.Ç. 24 yıldır evli, görücü usulüyle evlenmişler. A.Ç. ve eşi bir kamu kuruluşunda memur olarak çalışıyorlar. 23 yaşında üniversite öğrencisi olan bir oğulları đaha var. Evililiklerinin ilk yılları problemli geçmiş, Eşinin ailesi köy kökenliymiş bu nedenle düzen, temizlik ve görgü konusunda zaman zaman sorunlar yaşanıyormuş. Evlendikleri ilk yıl Ağri'da oturmuşlar. Oğlunu rahat ve sakin bir ortamda büyütmüş. Sonra Bandırma'ya tayinleri çıkmış. Karı-kocanın ailesi de orada oturuyormuş. N.Ç. nin doğumu ve çocukluğu sırasında eve çok fazla misafir gelmiş ve A.Ç. evde istediği gibi düzeni sağlayamamış. N.Ç. çocukluğunda hareketli ve $\mathrm{SÖz}$ dinlemeyen bir kızmış. A.Ç. Kızı doğunca işten ayrımış ve evde çocuklarıla ilgilenmiş. N.Ç. Ilkokula başlayınca annesi işe başlamış, ağabeyi de Anadolu Lisesini kazanıp yatılı olarak okumak üzere evden ayrımış. N.Ç. evde yalnız kalmış.

Problemler N.Ç. lișe 1. sınıfa başladığında ortaya çıkmiş. Anadolu Lisesinde okuyan N.Ç. ortaokulda üç yıl basketbol oynamış. $O$ dönemde çok kito aldığı için sıkı bir diyet uygulamış. Ağır spor ve sıkı diyet sonucunda dizinde ödem oluşmuş doktorlar spor yapmasını yasaklamış. Bu N.Ç. yi çok üzmüş. Bu sırada N.Ç. Iiseye başlamış ve ortaokulda samimi olduğu arkadaşlarından ayrılıp Mine adında yeni bir kız arkadaşla samimi olmuş Mine'nin ablası dini faaliyetleri olan biriymiş. Lise 1. sınıf bitiminde 
yaz tatilinde N.Ç. Ilk kez denize girmemeye, şort, kısa kollu bluz giymemeye ve namaz kılmaya başlamış. Anne baba çok üzülmüş ve sert tepkide bulunmuşlar. Ancak N.Ç. bu tutumundan vazgeçmemiş. Bundan sonra aile için çok kötü günler başlamış. Baba kızını takip ettiğinde dini toplantılara gittiğini, türbanlı kızlarla arkadaşlık ettiğini görmüş. Evde çok değişik dini kitaplar bulmuşlar. A.Ç. kızının eşyalarını not defterlerini karıştırmış ve bulduğu dini notları yırtmış. Bu N.Ç, yi çok kızdırmış. Evde çok şiddetli kavgalar olmuş ve N.Ç. ilk kez annesine hakaret etmiş. Anne ve babanin takipleri ve kontrol etme istekleri çok sıklaşmış. Anne baba asla kızlarının bu tür gruplarda yer almasını ve böyle bir tutum içinde olmasını istemiyor ve vazgeçirmeye çalışıyorlarmış. Ancak N.Ç. den ilk kez çok büyük bir dirençle karşılaşmışlar. Anne Mine ile olan arkadaşiığını bitirmesini istemiş. Sürekli arkadaşları ile olan teleton görüşmeleri takip alına alınmış. Tartışmalar zaman zaman büyük kavgalara dönüşmüş ve N.Ç. anne babasından dayak yemeye başlamış. Aile üyeleriyle hiçbir iletişimi kalmamış. Gittikçe içine kapanan mutsuz, dalgın, durgun, kimseyle konuşmayan, kendi dünyasında yaşayan bir kız haline gelmiş.

Bu süreçte A.Ç. kendisini tamamen kızına odaklamıştı N.Ç. nin davranışları hem onu çok ūzüyor hemde kızdırıyordu. Düzenlerini bozduğu için, kendisine bunları yaşattığı için N.Ç. den neíret ediyordu. Baba ise kızına karşı çok öfkeli, onu türbanlı görmektense öldürmeyi yeğleyeceğini söylemekteydi.

N.Ç. de anne-babasını sürekli küçümsüyor "siz boş insanlarsınız, çarkıfeleği seyrediyorsunuz" diyormuş "siz Müslümanlığınızı yaşayın ben de Müslümanlığımı yaşayayım, bana karışmayın" djyerek odasına çekiliyor ve dini kitapları okuyormuş. Ağabeyinin bira içmesine karşı çıkıyor, onun davranışlarını eleştiriyormuş. Zamanla iki kardeş arasındaki iletişim çok azalmış. Ağabeyinin N.Ç. yi aşağılamaya başlamasıyla iletişimleri tamamen kopma noktasına gelmiş. Bu arada anne baba da bu durumdan birbirlerini suçluyor ve kavga ediyorlarmış. Baba N.Ç. nin üniversiteye ancak kendi çizgilerinde olursa gidebileceği, aksi ha!de kızını evlatlıktan reddedeceği ya da öldüreceği mesajlarını veriyormuş.

N.Ç ile yapılan ilk görüşmede ailede yaşananlan ve problemlerin kaynağını; ailedeki iletişim sorunları, yaşanan kopukluklar, karşılıklı konuşmamanın ve birbirlerini anlamamanın getirdiği sıkıntılar olarak görơügünü belirtti. N.Ç. annesinin kendini acınası biri gibi gördügünü, kendisini bıraktığını, tüm sorunları kendisine bağladığını söyledi. Annesinin iyi gitmeyen bir evliliği olduğunu, iş hayatında sıkıntıları olduğunu dile getirdi. Ailede kendisine saygı duymadıklarını, düşüncelerine ve duygularına önem vermediklerini belirtti. Sorunlar başladığında onunla konuşmayı hep başkalarıyla konuşmaları ve aşırı tepki göstermeleri N.Ç. nin evde kendini daha yalnı ve üzgün hissetmesine neden olmuş. N.Ç. nin yaşadıklarının bit siyasi akıma kapııma olmadığı, kendi varoluşunu anlamak için yardım aradığı bunu da dinde bulmaya çalıştığı izlendi. N.Ç. aslında uyumlu ve mutiu bir ailesi olmasını istiyor ve sorunun çözümünün aile içinde gerçekleşeceğini, onlarla birlikte olmak istediğini dile getiriyordu. N.Ç. ile 2 görüşme yapıldıktan sonra Çocuk Psikiyatrisi ile işbirliğine girilerek aile görūşmeleri yapılmasına karar verildi. Anne-baba ve N.Ç. nin birlikte görüldüğŭ 4 aile 
görũşmesi yapıldı. Görüşmede soruntar aile üyeleri tarafından tanımlatılı. Aile üyeleri ilk kez sorunlarını bir arada konuşabilme firsatını buldu. Annenin çok depresif olduğu dikkati çekiyordu. Bir antidepresan başlandı ve takibe alındı. Babanın öfkeli tavrı yatıştırıldı ve iletişimi arttırma mesajı verildi. Görüşmeler sırasında birbirlerini daha iyi anlamaya başladılar. Anne ve baba N.Ç. üzerindeki kontrolü bırakıp onu anlamaya çalıştıkça evdeki gerginliklerde hızla azalmaya başladi. Anne-baba onun namaz kılmasına, kıyafetlerine karışmamaya başladılar. Anne eşyalarını karıştırmıyor, telefonla ya da takip ederek sürekli neler yaptığını izlemiyordu. Bu arada aile bir din görevlisiyle görüșüp N.Ç. nin dinle ilgili doğru bilgileri ondan almasını sağładılar.

Görüşmeler sonunda ailedeki öfke, kızgınlık, nefret gibi duygular yerini sevgiye, anlaşmanın verdiği rahatliğa ve ilgiye biraktı. Anne ile kızın paylaşımları arttı. Ağabeyi ve babasıyla da jletişim sorunlarını çözdüler.

N.Ç. o dönemde okulunda mutlu olmadığını, doktor olmak istediğini fark etti. Tekrar sınavlara hazırlanarak başka bir şehirdeki Tıp Fakültesini kazandı. Ailesi tarafından yurda yerleştirildi. Ihtiyacı olduğunda araması mesajı verildi.

\section{SONUÇ VE ÖNERILER}

Bu çocuklarını önemseyen bir ailenin yaşadığı bir aile krizi ve kızlarının yaşadığı bir gelişimsel krizi içermektedir. Çocuk odaklı olan aile kızlarıyla ilgili bu krizi çözmede yardıma ve işbirliğine çok açık oldukları için tedavi süreci başarılyla yürütüımüştür.

Gelişimsel yaşam krizleri büyüme ve gelişmeye ilişkin normal bir süreç olarak tanımlanabilir. Gelişimsel yaşam krizlerinin ortak teması presipite eden olayların kişilerin olgunlaşması sürecinde yatmasıdır. Ergenlik döneminde kriz potansiyeli taşıyan konular arasında meslek seçimi, değerlerin yerleşimi ve yakınlık kurma komponentlerini içeren kimlik temaları gündemdedir. Oldukça sıkıntılı olan kimliğin kazanıması sürecinde aile ve sosyal kurumların temel değerleri daha sonra benimsenmek üzere rededilir (Palabıyıkoğlu 1996). Bu olguda da N.Ç. nin kimlik kazanma döneminde bir arayış içinde oiduğu, arkadaşlarından etkilendiği ve aileden uzaklaştığı görülmektedir. N.Ç. nin dini gruplara yönelmesi kimlik arayışının getirdiği bir süreç olarak izlenmektedir. Aileye öfke, anlaşamama, yalnızlık hissi, varolma gereksinimi ailenin tamamiyle tersi ve karşı oldugu bir gruba üye olarak karşılianmıştır. Aile bu süreci katı ve esnekliği az olan yapısından dolayı sağlıkiı olarak değerlendirememiş ve zaman zaman şiddetin de olduğu sert tepkilerle kızlarını yanlış olduğuna inandıkları yoldan geri döndürmeye çalışmışlardır. Alledeki dengenin bozulması, aile üyelerinin iletişim sorunlarını ve problemlerini çözme becerilerinin zayıf oluşu anne-baba ergen arasındaki çatışmanın yardım almayı gerektirecek boyutlara gelmesine neden olmuştur. Aile üyeleri hem bireysel hem de aile terapileriyle ele alınarak önce içinde bulunulan problem tanımlanmış, aile üyeleri anlaşıldıklan ve problemlerini çözebileceklerine inanmıs daha sonra iletişim ve problem çözme becerileri arttırılarak ailede azalan bütünlük duygusunun artması sağlanmıştır. Görưşmeler sırasında aile üyelerinin birbirlerine olan olumsuz duyguları üzerinde çalışı $ı$ ış böylece ailedeki negatif duygu yükü boşaltilarak anne-baba-ergen arasındaki olumsuz etkileşim ortadan kaldırılmıştır. Aile 
kızlarının sağlıklı din bilgisine sahip olması için bu dönemde bu konuyla ilgili bir uzmandan bilgi almasını sağlamıştır. N.Ç. ailesiyle olan çatışmalarını çözmüş ve geleceği ile ilgili kararlarını gőzden geçirme fırsatını bulmuş ve istemediği bir işin eğitimini sürdürmekte olduğunu farkederek okulu bırakmış ve tekrar üniversite seçme sınavlarına girerek istediği okulu kazanmıştır. N.Ç. hala namaz kılmakta ancak çağdaş giyindiği kendine özen gösterdiŏgi daha mutlu canlı ve sosyal olduğu gözlenmektedir.

N.Ç. nin yeni gittiği kentte eğitimi sırasında uyum sorunlanı yaşayabileceği üzerinde durularak olası problemlet üzerinde konuşulmuştur. $\mathrm{Bu}$ dönemde iletişimin kopmaması ve zaman zaman telefonla araması mesajı verilerek görüşmeler tamamlanmıştır. 


$\begin{array}{lllll}K & R & \text { I } & Z\end{array}$

\section{KAYNAKLAR}

Ekşi A (1999). Adölesans Döneminde Uyum ve Davranış Sorunları, Ekşi A (eds) Ben Hasta Değilim Çocuk Sağlığı ve Hastalıklarının Psikososyal Yönü, Nobel Tip Kilabevi, 149-154.

Gander M.J. Gardiner WH (1993). Child and Adolescane Development, Çocuk ve Ergen Gelișimi. Ing Çev. Onur ve Ark. İmge Kitabevi Yayınları, S. 402-404.
Parman T (1,997). Ergenlik: Bir Giriş Yazısı. Psikiyatri, Psikoloji, Psikofarmokoloji, (5) Ek Sayı 4: 7-8.

Sayıl I, Palabıyıkoğlu R, Berksun O (1996). Kriz ve Krize Müdahale Kurs Notları, Kriz Merkezi Yayınlari, 72 Ofset Basımevi. 